\title{
Integrated Health Monitoring of Transportation Structures with Magnetic Fe-SMA Wires
}

\author{
Nathan Malone ${ }^{1}$, Peter Miller ${ }^{1}$, Hande $\mathrm{Ozcan}^{2}, J_{i \mathrm{Ma}^{1} \text {, Jeremy Schaffer }}^{3}$, and Ibrahim Karaman ${ }^{1 *}$. \\ ${ }^{1}$ Department of Materials Science \& Engineering, Texas A\&M University, College Station TX. \\ ${ }^{2}$ Department of Mechanical Engineering, Texas A\&M University, College Station, TX \\ ${ }^{3}$ Fort Wayne Metals Research Products Corporation, Fort Wayne
}

\begin{abstract}
In this work, the magnetization response of FeMnAlNi superelastic shape memory alloys (SMAs) is investigated under stress. Wires with a diameter of $0.5 \mathrm{~mm}$ were subjected to repeated abnormal grain growth heat treatments in order to obtain bamboo structured oligocrystalline grains that are necessary for superelasticity. Solution heat treated wires were aged at $200^{\circ} \mathrm{C}$ for $3 \mathrm{~h}$ to strengthen the austenite matrix. Tensile cyclic tests were performed at room temperature until failure, while the magnetization response of the wires was monitored using a hall sensor during loading and unloading in each cycle. It is observed that after each cycle, overall magnetization of the alloy decreases once the irrecoverable strain is introduced after large deformations and magnetization of the sample is inversely correlated with the irrecoverable strain. The findings of this work show that the magnetic shift in Fe-SMAs under deformation can be used a health monitoring tool in next generation structures to detect large deformations and cracks.
\end{abstract}

\section{Introduction}

Superelastic materials are a class of shape memory alloys (SMAs) that can generate large recoverable deformations upon the application of stress [1,2]. This property has been shown to limit the damages in structures caused by adverse events such as earthquakes and hurricanes [3-5]. Therefore, one of the most wellknown NiTi SMAs has been considered for a wide range of civil engineering applications as bracing systems [6,7], concrete reinforcement $[8,9]$, re-centering and damping element [10]. However, NiTi SMAs are expensive and difficult to process which limits their large-scale applications. Instead, Fe-SMAs are inexpensive alternatives to NiTi SMAs and they can be easily processed. Additionally, they show an interesting magnetization change during phase transformation from austenite to martensite under stress. The combination of these properties can be used to create a new health monitoring framework in next generation structures where embedded Fe-SMAs can serve as a load bearing and a sensing element at the same time.

The aim of the present work is to characterize the magnetic response of Fe-Mn-Al-Ni SMA under stress and investigate the evolution of the changes in the induced magnetization during superelastic transformation.

\section{Methods and experimental setup}

Heat treated rods with a nominal composition of Fe$34 \% \mathrm{Mn}-15 \% \mathrm{Al}-7.5 \% \mathrm{Ni}$ (at.\%) were cold-drawn into 0.5 $\mathrm{mm}$ diameter wires at room temperature with a total area reduction of $75 \%$. Thermomechanical processing details of the heat-treated rods are given in previous studies [11].

In order to generate bamboo-like coarse grained microstructure, wires were subjected to abnormal grain growth heat treatments as shown in Figure 1a. Wires with a gauge length of $50 \mathrm{~mm}$ were wrapped in a molybdenum envelope and encapsulated in a quartz tube under a high purity inert argon atmosphere. Encapsulated samples were then cyclically heat treated at $1200^{\circ} \mathrm{C}$ for $30 \mathrm{~min}$ and subsequently air cooled to room temperature (step 1 in Figure1a) for a total of 5 cycles. After abnormal grain growth process, wires were then solution heat treated at $1300^{\circ} \mathrm{C}$ for $30 \mathrm{~min}$ in a high purity inert argon atmosphere and quenched in water (step 2 in Figure 1a). In order to strengthen the bcc austenite matrix, nano-sized precipitates were formed through precipitation heat treatment at $200^{\circ} \mathrm{C}$ for $3 \mathrm{~h}$ indicated as step 3 in Figure 1a.

Microstructures of the wires were investigated using EBSD. Sample preparation was done through mechanical grinding and $0.04 \mu \mathrm{m}$ colloidal silica. Crystallographic orientation mapping of the wire parallel to the drawing direction is represented in Figure 1b. It is observed that, grains have their [011] direction aligned with the axis of the wire and possess strong [110] texture along the drawing direction. Grain size to wire diameter ratio $(d / D)$ is higher than 1 and grains span across the cross section of the wire, which is a prerequisite for superelasticity [12, 13].

\footnotetext{
* Corresponding author: ikaraman@tamu.edu
} 


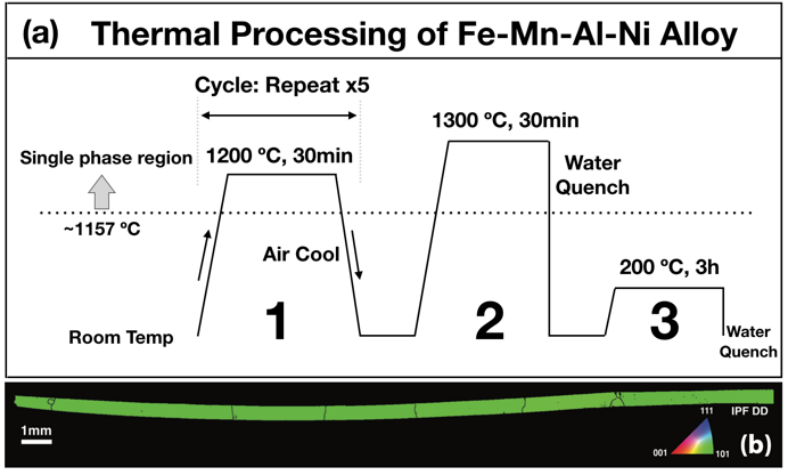

Fig. 1. (a) Thermal processing of $\mathrm{Fe}_{43.5} \mathrm{Mn}_{34} \mathrm{Al}_{15} \mathrm{Ni}_{7.5}$ (at.\%) wires. Step 1 generates the bamboo-like oligocrystalline grains via cycling between $1200^{\circ} \mathrm{C}$ and room temperature for 5 times. This is followed by a solution heat treatment at $1300^{\circ} \mathrm{C}$ for $30 \mathrm{~min}$ (step 2) and $200^{\circ} \mathrm{C}$ for $3 \mathrm{~h}$ (step 3) aging. (b) Demonstrates the electron backscatter diffraction (EBSD) crystallographic orientation map of the wire along drawing direction.

Superelastic responses of the wires were characterized using an electro-mechanical MTS uniaxial tension load frame at room temperature. An MTS LX1500 laser extensometer was used to measure tensile strain with a reflective tag directly placed to the wire. The gauge length of the wires was chosen as $50 \mathrm{~mm}$. Specimens were cyclically loaded and unloaded until failure with $1 \%$ incremental strain levels. Nominal deformation rate was chosen as $5 \times 10^{-4} \mathrm{~s}^{-1}$.

In order to measure magnetic properties of the wires under stress, a magneto-mechanical experimental setup was designed where stress, strain and magnetic flux could be measured simultaneously. Figures $2 \mathrm{a}$ and $\mathrm{b}$ demonstrate the 3D SolidWorks design and the actual experimental setup respectively.

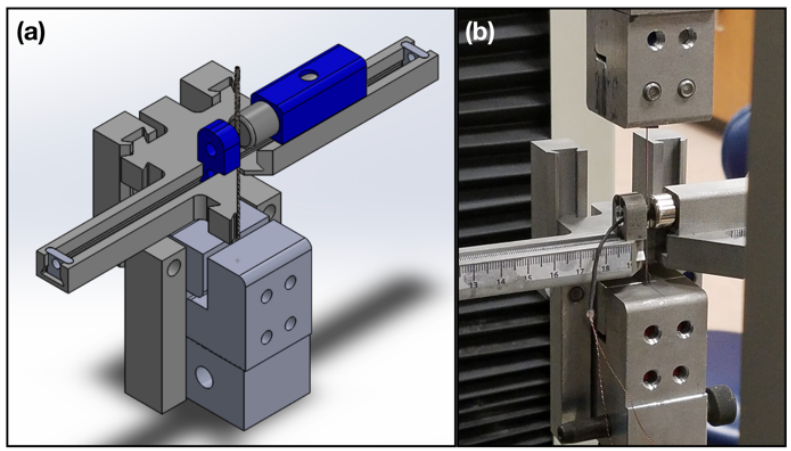

Fig. 2. (a) 3D SolidWorks model and (b) experimental setup for measuring magnetic properties of the FeMnAlNi wires under stress at room temperature.

Every component of the setup (including grips) were fabricated using a nonmagnetic aluminum alloy which has a magnetic relative permeability very close to vacuum (1.0) [14]. Therefore, magnetic interference of the setup with the material response was prevented during testing. The setup is designed to have a flat stage where a small $0.5 \mathrm{~T}$ cylindrical permanent magnet provides a bias field perpendicular to the loading direction, with a LakeShore Hall probe on the opposite side of the wire. Sensor data from the hall sensor is sent and recorded through the use of a LakeShore model 460 3-channel gaussmeter. Before each experiment, the hall probe is calibrated with a small zero gauss chamber provided by the manufacturer.

\section{Results and discussion}

Figure $3 \mathrm{a}$ shows the room temperature superelastic response of the oligocrystalline Fe-Mn-Al-Ni wire aged at $200{ }^{\circ} \mathrm{C}$ for $3 \mathrm{~h}$. The sample shows almost full recovery until $4-5 \%$, after which full recovery is no longer observed. Irrecoverable strain reaches a maximum value of $2 \%$ in the $8 \%$ strain level. Critical stress level of the wire is around $\sim 640 \mathrm{MPa}$ when it is aged at $200^{\circ} \mathrm{C}$ for $3 \mathrm{~h}$, which is $\sim 200 \mathrm{MPa}$ higher than previously reported values of wires having [011] texture [11, 12, 15]. On the other hand, hysteresis of the wire, which is defined as the average stress difference between the loading and unloading curve at $3 \%$ applied strain level, is measured as $\sim 150 \mathrm{MPa}$ similar to previous studies $[11,15]$. Stress drops are observed during forward transformation, which is a typical response of $\mathrm{Fe}-\mathrm{Mn}-\mathrm{Al}-\mathrm{Ni}$ wires having oligocrystalline grains $[11,15]$.
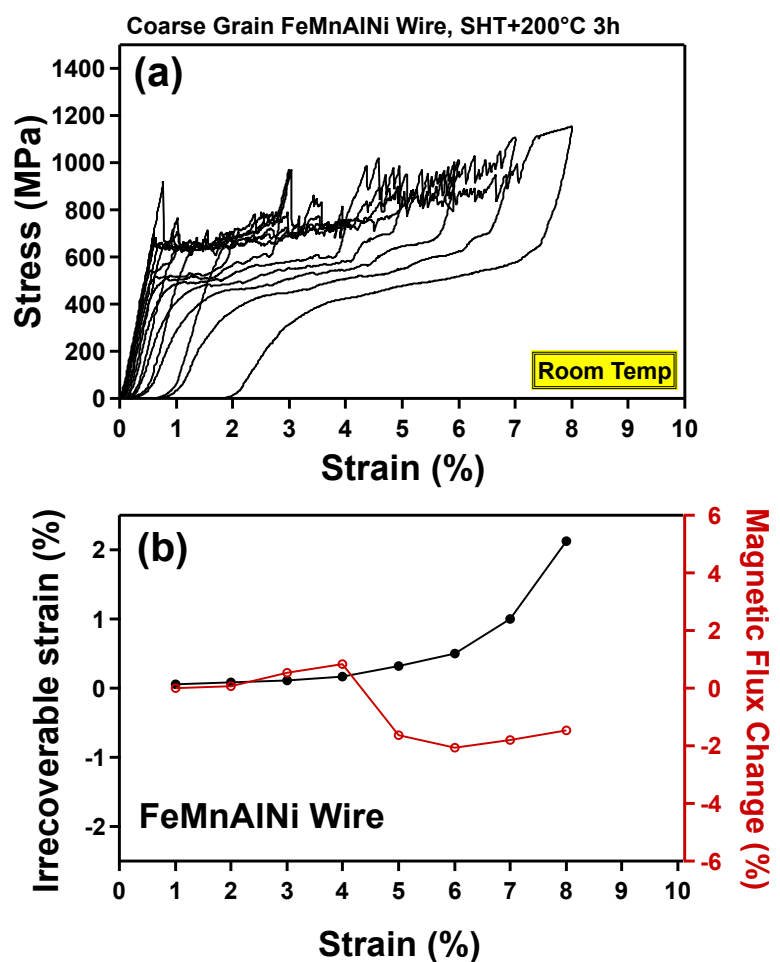

Fig. 3. Room temperature (a) superelastic tensile response and (b) corresponding magnetic response of oligocrystalline $\mathrm{Fe}_{43.5} \mathrm{Mn}_{34} \mathrm{Al}_{15} \mathrm{Ni}_{7.5}$ (at.\%) wire aged at $200{ }^{\circ} \mathrm{C}$ for 3 hours. Magnetic readings and irrecoverable strain are measured in each cycle after unloading.

The evolution of magnetic flux change in each applied strain level is shown in Figure 3b. This is compared against the irrecoverable strain in each cycle (represented as black dots in Figure 3b). Magnetic flux change represents the difference between the initial magnetic flux (undeformed state) and the magnetic flux measured at the end of each cycle. It is observed that, change in magnetic flux is initially constant, but decreases after $4 \%$ strain which coincides with the introduction of irrecoverable 
strain to the sample. This behavior suggests that the presence of remnant martensite in the microstructure has a significant effect on the magnetic response of the material. The reason for this behavior is a change in the material's magnetic state from ferromagnetic austenite to weak-magnetic martensite during transformation [16]. In Figure $3 \mathrm{~b}$, the magnetic flux change however, does not alter significantly after $6 \%$ strain. It is important to note that in the current study, measurements are taken from the middle of the wire with a sensor area of $32 \mathrm{~mm}^{2}$, However, actual transformation can start and propagate anywhere in the material. Therefore, one possible explanation of this constant magnetic behavior above $6 \%$ deformation is the location dependence of the transformation and its effect on the measured magnetic flux.

\section{Conclusions}

In the present study, the magnetic response change during superelasticity in Fe-Mn-Al-Ni alloys is investigated at room temperature. It is shown that oligocrystalline $\mathrm{Fe}$ $\mathrm{Mn}-\mathrm{Al}-\mathrm{Ni}$ wires with a $0.5 \mathrm{~mm}$ diameter show a magnetization change under deformation up to $8 \%$. A magnetization shift occurred as result of remnant martensite in the material and it is inversely correlated with the irrecoverable strain. This property can be harnessed as a tool to monitor and detect stresses and strains in next generation structures with integrated FeSMAs in a non-destructive fashion.

The authors would like to acknowledge the financial support from the Transportation Consortium of South-Central States through a grant from the U.S. Department of Transportation/University Transportation Center Program (Grant No. 69A3551747106).

\section{References}

1. Funakubo H. (1987). Shape Memory Alloys, Taylor and Francis.

2. Otsuka K., Wayman C.M. (1999). Shape Memory Materials, Cambridge University Press.

3. Billah A.M., and Alam M.S. (2012). Seismic performance of concrete columns reinforced with hybrid shape memory alloy (SMA) and fiber reinforced polymer (FRP) bars." Construction and Building Materials, 28(1), 730-742.

4. Billah A.H.M., and Alam M.S. (2015). Seismic fragility assessment of concrete bridge pier reinforced with superelastic shape memory alloy. Earthquake Spectra, 31(3), 1515-1541.

5. Saiidi M.S., Sadrossadat-Zadeh M., Ayoub C., Itani A. (2007). Pilot study of behavior of concrete beams reinforced with shape memory alloys. Journal of Materials in Civil Engineering, 19(6), 454-461.

6. Ozbulut O.E., and Hurlebaus S. (2010). Evaluation of the performance of a sliding-type base isolation system with a NiTi shape memory alloy device considering temperature effects. Engineering Structures, 32, 238-249.

7. Torra V., Isalgue A., Martorell F., Terriault P., Lovey F.C. (2007). Built in dampers for family homes via SMA: An ANSYS computation scheme based on mesoscopic and microscopic experimental analyses. Engineering Structures, 29(8), 1889-1902.

8. Saiidi M., O'Brien M., and Sadrossadat-Zadeh M. (2010). Cyclic response of concrete bridge columns using superelastic nitinol and bendable concrete. ACI Structural Journal, 106, 69-77.

9. Saiidi M.S., and Wang H. (2006). Exploratory study of seismic response of concrete columns with shape memory alloys reinforcement. ACI structural journal, 103(3).

10. Torra V., Martorell F., Lovey F.C., and Sade M.L. (2017). Civil engineering applications: specific properties of NiTi thick wires and their damping capabilities, a review. Shape Memory and Superelasticity, 3, 403-413.

11. Ozcan H., Ma. J., Wang, S.J., Karaman, I. Chumlyakov Y., Brown J., and Noebe R.D. (2017). Effects of cyclic heat treatment and aging on superelasticity in oligocrystalline Fe-Mn-Al-Ni shape memory alloy wires. Scripta Materialia, 134, 66-70.

12. Omori, T., Okano, M., and Kainuma, R., (2013). Effect of grain size on superelasticity in Fe-Mn-AlNi shape memory alloy wire. APL Materials, 1(3), 032103.

13. Omori, T., Iwaizako, H., and Kainuma, R. (2016). Abnormal grain growth induced by cyclic heat treatment in Fe-Mn-Al-Ni superelastic alloy. Materials \& Design. 101, 263-269.

14. Cullity B.D., and Hoboken N.J. (2009). Introduction to magnetic materials. Wiley/IEEE.

15. Ozcan H., Ma. J., Karaman I., Chumlyakov, Y.I., Santamarta R., Brown J., and Noebe R.D. (2018). Microstructural design considerations in Fe-Mn-Al$\mathrm{Ni}$ shape memory alloy wires: effects of natural aging. Scripta Materialia. 142, 153-157.

16. Ando K., Omori T., Ohnuma I., Kainuma R. and Ishida K. (2009). Ferromagnetic to weak-magnetic transition accompanied by bec to fcc transformation in Fe-Mn-Al alloy. Applied Physics Letters. 95, 212504. 